\section{Commentary: Anatomic resection after neoadjuvant TKI therapy- To be forewarned}

\author{
Andrew C. Chang, MD
}

In this case report, Chudgar and Jones ${ }^{1}$ describe findings encountered in 2 patients undergoing thoracoscopic pulmonary lobectomy after completing induction therapy with the third-generation tyrosine kinase inhibitor (TKI) osimertinib for locally advanced EGFR-mutant adenocarcinoma. Although cases involving the use of TKI therapy in the neoadjuvant setting have been reported previously, ${ }^{2,3}$ this case report includes well-described video documentation of the hilar fibrosis encountered and the meticulous, sharp dissection that might be needed for safe mobilization and anatomic resection. Such a fibrotic reaction, as demonstrated in the accompanying video clips, might be expected among patients who have completed preoperative radiation therapy but appears out of proportion to what might be expected with induction chemotherapy alone. Recent studies evaluating the role of immune checkpoint inhibition in the neoadjuvant setting suggest that similar tissue fibrosis is encountered, leading to a greater rate of thoracotomy. Notably, although the $\mathrm{NADIM}^{4}$ and $\mathrm{LCMC}^{5}$ trialists demonstrated that neoadjuvant immune checkpoint inhibition with either nivolumab or atezolizumab, respectively, is well tolerated, earlier reports of surgical experiences following nivolumab neoadjuvant therapy have noted that there may be a greater need for open resection. ${ }^{6}$

As the authors indicate, the decision to include novel, targeted therapy in the neoadjuvant preoperative setting should be undertaken after multidisciplinary review and

From the Michigan Medicine, University of Michigan, Ann Arbor, Mich.

Disclosures: The author reported no conflicts of interest.

The Journal policy requires editors and reviewers to disclose conflicts of interest and to decline handling or reviewing manuscripts for which they may have a conflict of interest. The editors and reviewers of this article have no conflicts of interest.

Received for publication Feb 21, 2021; revisions received Feb 21, 2021; accepted for publication Feb 25, 2021; available ahead of print March 2, 2021.

Address for reprints: Andrew C. Chang, MD, Michigan Medicine, University of Michigan, 1500 East Medical Center Drive, TC2120/5344, Ann Arbor, MI, 48109 (E-mail: andrwchg@med.umich.edu).

JTCVS Techniques 2021;7:298

2666-2507

Copyright (C) 2021 The Authors. Published by Elsevier Inc. on behalf of The American Association for Thoracic Surgery. This is an open access article under the CC BY-NCND license (http://creativecommons.org/licenses/by-nc-nd/4.0/).

https://doi.org/10.1016/j.xjtc.2021.02.047

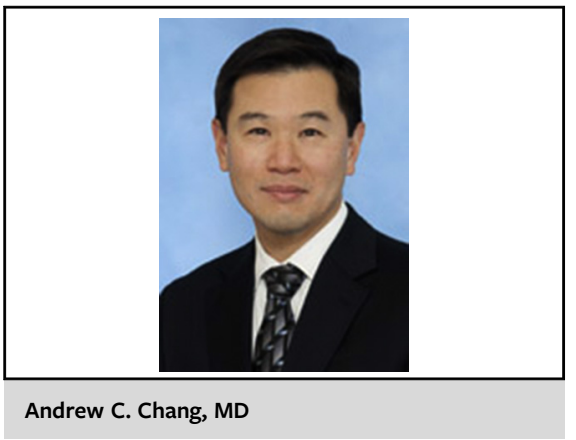

CENTRAL MESSAGE

This case report describes intraoperative findings in 2 patients undergoing thoracoscopic lobectomy after they had completed induction tyrosine kinase inhibitor therapy.

discussion, preferably under the auspices of a clinical trial, until the safety and long-term efficacy can be validated. Whether or not the intraoperative findings reported by the authors might indicate an idiosyncratic reaction, related to dosing regimen or duration of treatment or some other cause, their case report serves as a good visual reminder that attention to surgical technique remains paramount for the thoracic surgical oncologist.

\section{References}

1. Chudgar NP, Jones DR. Thoracoscopic lobectomy following neoadjuvant tyrosine kinase inhibitor treatment. J Thorac Cardiovasc Surg Tech. 2021;7:294-7.

2. Sakanoue I, Hamakawa H, Kaji R, Imai Y, Katakami N, Takahashi Y. Sleeve lobectomy for lung adenocarcinoma treated with neoadjuvant afatinib. J Thorac Dis. 2018;10:E170-4.

3. Yamamoto Y, Kodama K, Maniwa T, Takeda M. Surgical resection of advanced non-small-cell lung cancer after a response to EGFR-TKI: presentation of two cases and a literature review. J Cardiothorac Surg. 2017;12:98.

4. Provencio M, Nadal E, Insa A, García-Campelo MR, Casal-Rubio J, Dómine M, et al. Neoadjuvant chemotherapy and nivolumab in resectable non-small-cell lung cancer (NADIM): an open-label, multicentre, single-arm, phase 2 trial. Lancet Oncol. 2020;21:1413-22.

5. Lee JM, ed. P01.05 Surgical and clinical outcomes with neoadjuvant atezolizumab in resectable stage IB-IIIB NSCLC: LCMC3 trial primary analysis. Presented at: International Association for the Study of Lung Cancer 2020 World Conference on Lung Cancer, January 30, 2021, Singapore.

6. Bott MJ, Yang SC, Park BJ, Adusumilli PS, Rusch VW, Isbell JM, et al. Initial results of pulmonary resection after neoadjuvant nivolumab in patients with resectable non-small cell lung cancer. J Thorac Cardiovasc Surg. 2019;158:269-76. 